\title{
POST-THERAPY OUTCOME AND ECHOCARDIOGRAPHIC ANALYSIS AT THREE WEEKS OF ELDERLY PATIENTS WITH ACUTE MYOCARDIAL INFARCTION FOLLOWING THROMBOLYSIS
}

\author{
Vinod Kumar'1, Ritu Bhagat2, Roopali Jandyal ${ }^{3}$ \\ ${ }_{1}^{1}$ Consultant Physician, JK Health Services, Jammu and Kashmir, India. \\ ${ }^{2}$ Senior Resident, Department Pathology, GMC, Jammu and Kashmir, India. \\ ${ }^{3}$ Senior Resident, Department Pathology, GMC, Jammu and Kashmir, India.
}

\section{ABSTRACT}

\section{BACKGROUND}

Once severe ischemia has lasted for about 20 minutes, myocardial necrosis ensues, affecting the subendocardium first and then proceeding in a time dependent wave front to reach epicardium about 4 to 6 hours later. Restoration of blood flow before necrosis is transmural, arrests the progression of necrosis and salvages the still viable but ischemic myocardium that would otherwise proceed to necrosis. We wanted to assess the occurrence of complications of half dose of streptokinase versus full dose of streptokinase in three weeks follow-up following thrombolysis therapy.

\section{METHODS}

Sixty elderly patients with acute myocardial infarction were enrolled in the study, presenting within 12 hours of onset of symptoms and having no contra-indication to thrombolytic therapy at GMC, Jammu for a period of one-year w.e.f. Nov. 2017 to Oct. 2018.

\section{RESULTS}

Out of the total 60 cases included in our study, $30(50 \%)$ were assigned to the study group and $30(50 \%)$ were included in the control group. Overall, 46 (76.7\%) males and 14 (23.3\%) females were included in the study.

\section{CONCLUSIONS}

Low dose streptokinase also achieved post-therapy outcome comparable to the standard dose, as assessed clinically and echocardiographically in a short-term follow-up of three weeks. Also, low dose streptokinase (7.5 lakh units) infusion was found to be associated with a lower incidence of haemorrhagic complications as compared to conventional full dose (1.5 million units) streptokinase infusion.

\section{KEY WORDS}

Acute Myocardial Infarction, Echocardiography, Post-Therapy Outcome

HOW TO CITE THIS ARTICLE: Kumar V, Bhagat R, Jandyal R. Post-therapy outcome and echocardiographic analysis at three weeks of elderly patients with acute myocardial infarction following thrombolysis. J. Evolution Med. Dent. Sci. 2019;8(22):1785-1788, DOI: $10.14260 /$ jemds/2019/392

\section{BACKGROUND}

Acute myocardial infarction (AMI) has been found to be the leading cause of death in elderly over the age of 65 years. It accounts for $80 \%$ of deaths in the elderly, with $6.8 \%$ of the population of India over 60 years. The mortality in elderly is two-times more after AMI as compared to the younger counterparts. ${ }^{1}$ The mortality of infarction increases very steeply with increasing age $>65$ years with 1 -month mortality in the range of $20-30 \% .^{2}$ Although early studies suggested an increased risk of haemorrhagic complications in the elderly patients receiving thrombolytic therapy,3,4 large multicentric trials have shown that this fear is unfounded.5,6 However, two recent studies have shown that streptokinase in conventional doses of 1.5 million units was associated with excess of strokes in patients aged more than 70 years. ${ }^{7}$

'Financial or Other Competing Interest': None.

Submission 03-04-2019, Peer Review 17-05-2019,

Acceptance 23-05-2019, Published 03-06-2019.

Corresponding Author:

Dr. Ritu Bhagat,

$M D$, Department Medicine,

GMC, Jammu and Kashmir,

India.

E-mail: ritubhagat8600@gmail.com

DOI: $10.14260 /$ jemds $/ 2019 / 392$

\section{(c) ()$_{\mathrm{BY}} \odot$}

The risk of cerebral haemorrhage following thrombolysis is small, about $1-2$ per $1000^{8}$. Though the traditional dose of streptokinase fixed at 1.5 million units, ${ }^{9}$ has been widely accepted, some recent clinical trials have provided noninvasive evidence of reperfusion with half dose streptokinase with comparable results. ${ }^{10,11}$

\section{METHODS}

The present work is a hospital based cross- sectional study for a period of one year from nov. 2017 to oct. 2018 that included 60 patients of acute myocardial infarction in elderly that presented within 12 hours of onset of symptoms and had no contraindication to administration of streptokinase for thrombolysis. The patients were randomized into two groups, Randomisation and was done by using computer generated random number table, the study group to whom 7.5 lakh units of streptokinase was administered intravenously over 30 minutes, while the control group received the standard dose of 1.5 million units of streptokinase intravenously over one hour. Detailed history was taken, and thorough clinical and biochemical profile was done. AMI was diagnosed by criteria defined by World Health Organization (WHO). Electrocardiogram (ECG) was recorded both at baseline and after 3 hours. Echocardiographic analysis of left ventricular function left ventricular ejection fraction and left ventricular diastolic dysfunction were calculated at three weeks. Got approval from IEC and consent was taken from all patients. 


\begin{tabular}{|c|c|c|c|}
\hline \multirow{2}{*}{ Subjects } & \multicolumn{2}{|c|}{ Gender } & \multirow{2}{*}{ Total } \\
\cline { 2 - 3 } & Male No. (\%) & Female No. (\%) & \\
\hline Study group & $21(70.0)$ & $9(30.0)$ & $\mathbf{3 0 ( 1 0 0 . 0 )}$ \\
\hline Control group & $25(83.3)$ & $5(16.7)$ & $30(100.0)$ \\
\hline Total & $46(76.7)$ & $14(23.3)$ & $60(100.0)$ \\
\hline \multicolumn{3}{|c|}{ Table 1. Gender Wise Distribution of Cases } \\
\hline
\end{tabular}

\begin{tabular}{|c|c|c|c|c|c|}
\hline \multirow[b]{2}{*}{ Subjects } & \multicolumn{4}{|c|}{ Age Group (in Years) } & \multirow[b]{2}{*}{$\begin{array}{c}\text { Total No. } \\
\text { (\%) }\end{array}$} \\
\hline & $\begin{array}{c}\leq 65 \text { No. } \\
(\%)\end{array}$ & \begin{tabular}{|c|}
$66-69$ \\
No. (\%)
\end{tabular} & $\begin{array}{c}70-75 \\
\text { No. (\%) }\end{array}$ & $\begin{array}{c}>75 \text { No. } \\
(\%)\end{array}$ & \\
\hline Study group & $10(33.3)$ & $6(20.0)$ & $10(33.3)$ & $4(13.3)$ & $30(100.0)$ \\
\hline Control group & $7(23.3)$ & $11(36.7)$ & $9(30.0)$ & $3(10.0)$ & $30(100.0)$ \\
\hline Total & $17(28.3)$ & $17(28.3)$ & $19(31.7)$ & 7 (11.7) & $\begin{array}{c}60 \\
(100.0) \\
\end{array}$ \\
\hline \multicolumn{6}{|c|}{ Table 2. Age Wise Distribution of Cases } \\
\hline
\end{tabular}

\begin{tabular}{|c|c|c|c|}
\hline & \multicolumn{3}{|c|}{ Mean \pm Standard Deviation } \\
\hline Subjects & Pulse (min) & $\begin{array}{c}\text { Systolic Blood } \\
\text { Pressure (mmHg) }\end{array}$ & $\begin{array}{c}\text { Diastolic Blood } \\
\text { Pressure (mmHg) }\end{array}$ \\
\hline Study group & $83.07 \pm 13.80$ & $125.13 \pm 19.66$ & $77.47 \pm 11.78$ \\
\hline Control group & $76.67 \pm 11.90$ & $133.40 \pm 25.51$ & $83.00 \pm 12.36$ \\
\hline $\begin{array}{c}\text { Table 3. Comparative Evaluation of Mean Values of Hemodynamic } \\
\text { Parameters of Study Group and Control Group }\end{array}$
\end{tabular}

\begin{tabular}{|c|c|c|c|}
\hline $\begin{array}{l}\text { Site of Myocardial } \\
\text { Infarction (MI) }\end{array}$ & $\begin{array}{l}\text { Study Group } \\
\text { No. (\%) }\end{array}$ & $\begin{array}{l}\text { Control Group } \\
\text { No. (\%) }\end{array}$ & $\begin{array}{l}\text { Total No. } \\
\text { (\%) }\end{array}$ \\
\hline Antero-inferior MI & $1(3.3)$ & - & $1(1.7)$ \\
\hline Antero-lateral & $1(3.3)$ & - & $1(1.7)$ \\
\hline Antero-lateral MI & $1(3.3)$ & - & $1(1.7)$ \\
\hline Antero-septal MI & $1(3.3)$ & - & $1(1-7)$ \\
\hline AWMI & $18(60.0)$ & $14(46.7)$ & $32(53.3)$ \\
\hline Inferolateral MI & $1(3.3)$ & $1(3.3)$ & $2(3.3)$ \\
\hline IWMI & $7(23.3)$ & $15(50.0)$ & $22(36.7)$ \\
\hline Total & $30(100.0)$ & $30(100.0)$ & $60(100.0)$ \\
\hline \multicolumn{4}{|c|}{$\begin{array}{c}\text { Table 4. Distribution of Myocardial Infarction Sites in Study Group } \\
\text { Versus Control Group }\end{array}$} \\
\hline
\end{tabular}

\begin{tabular}{|c|c|c|c|c|}
\hline \multirow{2}{*}{ Subjects } & \multicolumn{3}{|c|}{ Killip Class } & \multirow{2}{*}{ Total } \\
\cline { 2 - 4 } & Class I & Class II & Class III & \\
\hline Study group & $23(76.7)$ & $7(23.3)$ & - & $30(100.0)$ \\
\hline Control group & $10(33.3)$ & $18(60.0)$ & $2(6.7)$ & $30(100.0)$ \\
\hline Total & $33(55.0)$ & $25(41.7)$ & $2(3.3)$ & $60(100.0)$ \\
\hline Table 5. Distribution of Killip Class at Presentation in The Study \\
Group Versus the Control Group \\
\hline
\end{tabular}

\begin{tabular}{|c|c|c|c|}
\hline Risk Factors & $\begin{array}{c}\text { Study Group } \\
(\mathbf{n = 3 0 )} \text { No. (\%) }\end{array}$ & $\begin{array}{c}\text { Control Group } \\
(\mathbf{n = 3 0 )} \text { No. (\%) }\end{array}$ & $\begin{array}{c}\text { 'p'-Value } \\
\text { (z-test) }\end{array}$ \\
\hline Smoking & $18(60.0)$ & $20(66.67)$ & $0.352 \mathrm{NS}$ \\
\hline Hypertension & $16(53.33)$ & $14(46.67)$ & $0.358 \mathrm{NS}$ \\
\hline Diabetes & $8(26.67)$ & $4(13.33)$ & $0.180 \mathrm{NS}$ \\
\hline Family H/o CAD & $6(20.0)$ & $8(26.67)$ & $0.333 \mathrm{NS}$ \\
\hline Hyperlipidaemia & $4(13.33)$ & $12(40.0)$ & $0.493 \mathrm{NS}$ \\
\hline Table 6. Distribution of Coronary Risk Factors in The Study Group \\
Versus the Control Group \\
\hline \multicolumn{4}{|c|}{ NS Non-significant } \\
\hline
\end{tabular}

\begin{tabular}{|c|c|c|}
\hline & \multicolumn{2}{|c|}{ Mean \pm Standard Deviation } \\
\hline Subjects & $\begin{array}{c}\text { Therapeutic Window } \\
\text { (Hours) }\end{array}$ & $\begin{array}{c}\text { Time to Pain Relief after } \\
\text { STK (Hours) }\end{array}$ \\
\hline Study group & $6.32 \pm 2.23$ & $5.90 \pm 4.76$ \\
\hline Control group & $4.90 \pm 1.96$ & $5.61 \pm 3.36$ \\
\hline \multicolumn{2}{|c|}{ Table 7. Comparative Evaluation of Therapeutic Window to } \\
Thrombolysis and Time to Pain Relief in The Study Group and the \\
Control Group \\
\hline
\end{tabular}

\begin{tabular}{|c|c|c|c|c|c|}
\hline \multirow{2}{*}{$\begin{array}{l}\text { Time from STK } \\
\text { to Peak CPK- } \\
\text { MB (Hours) }\end{array}$} & \multicolumn{2}{|c|}{ Study Group $(n=30)$} & \multicolumn{2}{|c|}{$\begin{array}{c}\text { Control Group } \\
(n=30)\end{array}$} & \multirow{2}{*}{$\begin{array}{l}\text { 'p'- Value } \\
\left(\chi^{2}-\right. \\
\text { test) }\end{array}$} \\
\hline & \begin{tabular}{|c|}
$F c \geq 0.5$ No. \\
$(\%)$
\end{tabular} & \begin{tabular}{|c|} 
Fc $<0.05$ \\
No. $(\%)$ \\
\end{tabular} & $\begin{array}{l}F c \geq 0.5 \\
\text { No. }(\%)\end{array}$ & $\begin{array}{c}\text { Fc }<0.05 \\
\text { No. }(\%)\end{array}$ & \\
\hline 0 to $<12$ & $22(73.3)$ & - & $16(53.3)$ & $2(6.7)$ & $0.13 \mathrm{NS}$ \\
\hline 12 to 24 & $4(3.3)$ & $4(13.3)$ & $8(26.7)$ & $4(13.3)$ & \\
\hline \multicolumn{6}{|c|}{$\begin{array}{c}\text { Table 8. Comparison Between Reperfusion by Combined Criteria- } \\
\text { Fractional Change and Time from STK to Peak CPK-MB in Study } \\
\text { Group Versus Control Group }\end{array}$} \\
\hline \multicolumn{6}{|c|}{ NS $=$ Non-significant } \\
\hline
\end{tabular}

\begin{tabular}{|c|c|c|c|}
\hline Complications & $\begin{array}{c}\text { Study Group } \\
(\mathrm{n}=30) \text { No. (\%) }\end{array}$ & $\begin{array}{c}\text { Control Group } \\
(\mathrm{n}=30) \text { No. (\%) }\end{array}$ & $\begin{array}{c}\text { p-Value } \\
\text { (Z-Test) }\end{array}$ \\
\hline Minor bleed & - & $2(6.6)$ & 0.016 \\
\hline Major bleed & - & - & - \\
\hline Anaphylaxis & - & - & - \\
\hline Hypotension & - & - & - \\
\hline \multicolumn{3}{|c|}{ Table 9. Comparison Between Complications Following } \\
Streptokinase Infusion in Study and Control Groups \\
\hline
\end{tabular}

\begin{tabular}{|c|c|c|c|}
\hline \multirow{2}{*}{ Subjects } & \multicolumn{2}{|c|}{ Post MI Angina } & \multirow{2}{*}{ Total No. (\%) } \\
\hline & Negative No. (\%) & Positive No. (\%) & \\
\hline Subject group & $28(93.3)$ & $2(6.7)$ & $30(100.0)$ \\
\hline Control group & $30(100.0)$ & - & $30(100.0)$ \\
\hline Total & $58(96.7)$ & $2(3.3)$ & $60(100.0)$ \\
\hline \multicolumn{4}{|c|}{$\begin{array}{l}\text { Table 10. Comparison Between Occurrence of Post-Myocardial } \\
\text { Infarction (MI) Angina in Study Group Versus Control Group }\end{array}$} \\
\hline
\end{tabular}

\section{Statistical Analysis}

The data was collected and analysed using standard statistical chi - square test, $\mathrm{P}<0.05$ statistically significant. Data was entered in Microsoft excel and analysis was done using SPSS version 22.

\section{RESULTS}

The present study titled "Post-therapy outcome and echocardiographic analysis at three weeks of elderly patients with acute myocardial infarction following thrombolysis therapy" was conducted in Postgraduate Department of Medicine, Government Medical College Hospital, Jammu from November 2017 to October 2018. All the patients included in the study had presented within 12 hours of onset of symptoms and had no contraindication to administration of streptokinase for thrombolysis. The observations made were considered as follows:

\section{Post-Therapy Outcome}

1. Clinical.

2. By echocardiography.

Among clinical criteria to assess post-therapy outcome, the criteria included were minor bleed, major bleed, anaphylaxis and hypotension.

\section{DISCUSSION}

Sixty elderly patients with acute myocardial infarction were enrolled in the study, presenting within 12 hours of onset of symptoms and having no contra-indication to thrombolytic therapy. The patients included in the study were randomized into two groups - 30 patients in the study (Cases) group were thrombolysed with 7.5 lakh units of streptokinase (half dose) over thirty minutes while the rest 30 patients in the control group were administered 1.5 million units of streptokinase (Conventional full dose) over one hour. Post-therapy outcome and echocardiographic analysis at three weeks of 
patients with acute myocardial infarction following thrombolysis therapy were done.

\section{Baseline Characteristics}

Both, the study and the control groups were matched for age and gender. The mean age of the patients in the study group (cases) was $69.33 \pm 5.78$ years, while that of control group was $69.00 \pm 4.83$ years. Majority of the patients (19) were observed to be in the age group of 70-75 years in the study as well as control group. In the study group (Cases), 9 (30\%) were females and $21(70 \%)$ were males, while as in control group $5(16.7 \%)$ were females and $25(83.3 \%)$ were males. Overall, 14 (23.3\%) females and 46 (76.7\%) males were included in the study. Four and three patients were aged more than 75 years in the study and control groups, respectively. Both the groups were matched for gender and age. This was comparable with the age and gender groups of other studies.

Mean pulse rate of patients in the study group (Cases) was $86.07 \pm 13.08$ per minute while as those of the control group was $76.67 \pm 11.90$ per minute. Mean systolic blood pressure of patients in the study group (cases) was $125.13 \pm$ $19.65 \mathrm{mmHg}$ and in the control group was $133.40 \pm 25.50$ $\mathrm{mmHg}$, respectively. Mean diastolic blood pressure of patients in the study group (cases) was $77.47 \pm 11.77 \mathrm{mmHg}$ and $83.00 \pm 12.36 \mathrm{mmHg}$ in the Control group.

Majority of the patients in the study as well as control group had anterior wall myocardial infarction (53.3\%) followed by inferior wall myocardial infarction (36.7\%). Both the study and control groups were matched for distribution of infarct sites.

Most of the patients were in Killip class I and II at presentation in the study (Cases) as well as the control group. Twenty-three in the study group and 10 in the control group were in Killip class I, while 7 in the study and 18 in the control group were in Killip class II. None of the patients in the study group were in Killip Class III, while as 2 patients in the control group were in Killip class III. None of the patients were having cardiogenic shock at the time of presentation when administered streptokinase. Severity of cardiac dysfunction was similar in both the study and the control group.

Both the groups were matched with respect to Killip class at presentation. The major risk factor in both the groups was smoking, accounting for $60 \%$ (18 cases) and 66.67\% (20 cases) in the study and the control group, respectively. This was followed by hypertension as a risk factor, comprising $53.33 \%$ (16 cases) and $46.67 \%$ (14) in the study and the control groups, respectively. No statistically significant difference was found between study and control groups regarding distribution of risk factors.

As per the study protocol, only those patients coming within 12 hours of onset of typical symptoms of acute myocardial infarction were included in the study. The mean therapeutic window (i.e. time from onset of cardiac pain to administration of streptokinase) in the study group was 6.32 \pm 2.23 hours while as those in the control group was $4.90 \pm$ 1.95 hours. No statistically significant difference was found in the therapeutic window of both the groups.

The mean time to pain relief from streptokinase infusion in the study group (cases) was $5.90 \pm 4.75$ hours compared to $5.61 \pm 3.22$ hours in the entire control group. $73.33 \%$ (22) of patients had complete pain relief within 6 hours of completion of streptokinase infusion in the study group (Cases), 60\% (18) of the patients had complete pain relief within 6 hours of completion of streptokinase therapy in the control group. This was comparable with the studies of Sivan et al. ${ }^{11}$ and Ahmed et al. ${ }^{9}$ Reperfusion is characterized by a rapid progressive decrease in pain intensity within 30 minutes of onset of its abatement (Shah et al.). ${ }^{12}$ However, this is a subjective phenomenon and no definite time period has been documented to signify reperfusion.

Reperfusion using the criterion of fractional change $(\mathrm{Fc})$ on ECG was achieved in $86.67 \%$ (26) and $80 \%$ (24) of the patients in the study and the control group, respectively. The difference between the two groups by chi-square test was $\mathrm{p}=$ 0.2 , which is not statistically significant. According to fractional change, the patients were said to be re-perfused if $\mathrm{Fc} \geq 0.5$ and not re-perfused if $\mathrm{Fc}<0.5$. A fractional change value of $\mathrm{Fc} \geq 0.5$ had been found to $67 \%$ specific and $93 \%$ sensitive for predicting a patent artery (Hogg et al.). ${ }^{13}$

In a study taking time from streptokinase infusion to peak CPK as a criterion for reperfusion, it was found that peaking of CPK occurred at $9.7 \pm 6.3$ and $12.3 \pm 4.8$ hours in those receiving 7.5 lakh units and 1.5 million units of streptokinase, respectively (difference not statistically significant) [Gottlich et al].14 In this study, in the group receiving, 7, 50, $000 \mathrm{IU}$ of streptokinase, 89\%) patients showed peaking of CPK-MB within 12 hours, while $67 \%$ of patients did so in the group given 1.500, $000 \mathrm{IU}$. This compares well with the data of the present study.

The results of our study also corroborate with those of Sivan et al ${ }^{11}$ who analysed the efficacy and safety of streptokinase in full conventional dose (15 million units), half dose (7.5 lakh) and no thrombolysis in the elderly population (> 75 years). Successful thrombolysis in their study was defined as ST-segment resolution of $50 \%$ or more. They concluded that half dose (7.5 lakh units) streptokinase has equal efficacy, better clinical outcome, and reduced rate of complications as compared to full dose of streptokinase.

\section{Post-Therapy Outcome}

Considering the complication rate, the criteria to assess posttherapy outcome/complications clinically included any minor bleed, major bleed, anaphylaxis and haemorrhage. In our study, there was a greater incidence of minor bleed in the control group (Patients receiving 1.5 million units of streptokinase) which was statistically significant. However, no major bleed or any other complication was encountered either in the study group (Cases) or the control group following thrombolytic therapy. Thus, 7.5 lakh units of streptokinase was safer in elderly patients as compared to 1.5 million units in terms of minor bleeding complications.

However, post-myocardial infarction angina occurred in 2 $(6.7 \%)$ cases among the study group while as no such event occurred in the control group.

\section{Echocardiographic Analysis at Three Weeks}

The results obtained on echocardiographic analysis of patients at 3 weeks after acute myocardial infarction showed that the left ventricular ejection fraction (LVEF) ranged from 44 to $59 \%$ in the study group (Cases) and 41 to $57 \%$ in the control group. Mean LVEF in the study group (Cases) was $50.33 \pm 3.92$ while in the control group was $49.87 \pm 4.94$ 
there was no statistically significant difference of left ventricular ejection fraction at 3 weeks in the two groups as assessed by t-test ( $p=0.687)$. On correlating the echo evaluated LVEF at 3 weeks in patients with reperfusion by fractional change, it was found that the mean LVEF in those re-perfused by Fc criterion was $51.82 \%$ and $53.10 \%$ in the study and control groups, respectively. The t-test for significance gave p-value of 0.375 (not statistically significant). Thus, thrombolysis with either low (7.5 lakh units) or standard dose (1.5 million units) produces similar variation in left ventricular ejection fraction (LVEF).

In a study, the global ejection fraction at 3 months using radionucleotide ventriculography was $50 \pm 14$ and $45 \pm 16$ in low and standard dose streptokinase, respectively (Six et al). 15

Left ventricular diastolic dysfunction (LVDD) assessed by echo at the end of three weeks post-myocardial infarction was present in $22(73.3 \%)$ patients among the study group (cases) and $24(80.0 \%)$ patients among the control group. Two-tailed significance (chi-square test) for both the groups came to be 0.761 , which was statistically not significant implying that low and standard dose of streptokinase do not alter the post-myocardial infarction outcome in terms of left ventricular diastolic dysfunction.

Reperfusion leads to better left ventricular ejection fraction and less ventricular diastolic dysfunction in the postmyocardial infarction period as documented by other studies (White et al). ${ }^{16}$

\section{CONCLUSIONS}

In the present study, we conclude that low dose streptokinase also achieved post-therapy outcome comparable to the standard dose, as assessed clinically and echocardiographically in a short-term follow-up of three weeks. Also, low dose streptokinase (7.5 lakh units) infusion was found to be associated with a lower incidence of haemorrhagic complications as compared to conventional full dose (1.5 million units) streptokinase infusion.

\section{REFERENCES}

[1] Chopra KL. Thrombolytics and antithrombotics for acute coronary syndromes in the elderly. The Cardio Thoracic J 1996;2(4):9-13.

[2] Sleight P. Is there an age limit for thrombolytic therapy? Am J Cardiol 1993;72(19):G30-G33.

[3] Aldrich MS, Sherman SA, Greenberg HS. Cerebrovascular complications of streptokinase infusion. JAMA 1985;253(12):1777-9.

[4] Lew AS, Hod H, Cercek B, et al. Mortality and morbidity rates of patients older and younger than 75 years with acute myocardial infarction treated with intravenous streptokinase. Am J Cardiol 1987;59(1):1-5.
[5] GISSI. Effectiveness of intravenous thrombolytic treatment in acute myocardial infarction. Lancet 1986;1(8478):397-402.

[6] Muller DWM. Topol and Blood Institute. Morbidity and mortality chartbook on cardiovascular, lung and blood diseases. Bethesda, MD: US Department of Health and Human Services, Public Health Service, National Institute of Health, May 1992.

[7] Maggioni AP, Franzosi MG, Santoro E, et al. The risk of stroke in patients with acute myocardial infarction after thrombolytic and anti-thrombolytic treatment. GISSI-2 and the International Study Group. N Engl J Med 1992;327(1):1-6.

[8] Battershill PE, Benfield P, Goa KL. Streptokinase - a review of its pharmacology and therapeutic efficacy in acute myocardial infarction in older patients. Drugs Aging 1994;4(1):63-86.

[9] Ahmed I, Ishaq M. ECG and enzymatic indicators of therapeutic success after intravenous streptokinase for acute myocardial infarction - a pilot study. J Pak Med Assoc 1992;42(12):288-90.

[10] Bose CC, Balkrishan S, Satyavarthy, et al. Prospective study of safety and efficacy of 7.5 lakh units STK in AMI in Indian patients. Thrombolysis Update 1996;4(3):7-11.

[11] Sivan R, Chockalingam V, Subramanian T, et al. Comparative study of 7.5 lakh and 15 lakh units of streptokinase therapeutic issues in an elderly population with acute myocardial infarction. Indian Heart J 2003;55(5):149.

[12] Shah PK, Cercek B, Lew AS, et al. Angiographic validation of bedside markers of reperfusion. J Am Coll Cardiol 1993;21(1):55-61.

[13] Hogg KT, Hornung RS, Howie CA, et al. Electrocardiographic prediction of coronary artery patency after thrombolytic treatment in acute myocardial infarction: use of the ST segment as noninvasive marker. Br Heart J 1988;60(4):275-80.

[14] Gottlich C, Cooper B, Schumacher JR, et al. Do different doses of intravenous streptokinase after the frequency of coronary reperfusion in acute myocardial infarction? Am J Cardiol 1988;62(13):843-6.

[15] Six AJ, Louwerenburg HW, Braams R, et al. A doubleblind randomized multi-center dose-ranging trial of intravenous streptokinase in acute myocardial infarction. Am J Cardiol 1990;65(3):119-23.

[16] White HD, Norris RM, Brown MA, et al. Effect of intravenous streptokinase in left ventricular function and early survival after acute myocardial infarction. $\mathrm{N}$ Engl J Med 1987;317:850-5. 